\title{
Parameters, Factors and Criteria of Evaluation of Professional Development by Heads of Schools
}

\author{
Liliia Martynets, Hanna Davydenko, Iryna Denysovets, Sandeep Kumar Gupta
}

\begin{abstract}
The article considers parameters, factors and criteria of evaluation of professional development of teachers by heads of school. It was determined that evaluation of professional development of a teacher of the general educational institutions is implemented according to the following parameters: the readiness of a teacher of the general education institution for pedagogical activity, the content of the activity of the teacher of the general education institution, and the result of educational work of the teacher of the general educational institution. It was highlighted that the parameter "The readiness of a teacher of the general education institution for pedagogical activity" consists of the following factors: continuing education and personal qualities of a teacher. It was revealed that the parameter "The content of the activity of the teacher of the general education institution" is determined by such factors as professional duties and creative pedagogical activity. It was also specified that the parameter "The result of pedagogical activity of the teacher of the general educational institution" implies the factor of a teacher's social activity.

The article reveals the results of diagnostics of teachers professional development evaluation by school administrators via the level of the readiness for pedagogical activity, the content and the result of educational work of a teacher of the general education institution.
\end{abstract}

Keywords: Professional Development, A Teacher, pedagogical Activity, Parameter, Factor, Criterion.

\section{INTRODUCTION}

The national development strategy of education in Ukraine for the period until year 2021 announces strengthening of human capacity within the education system, personal development in terms of individual abilities and needs on the ground of lifelong education, training the teaching staff on the basis of its own continuing professional and creative growth, stimulating high-quality educational work based on the objective evaluation specified in the requirements of educational and professional programs. In accordance with it, top-priority tasks of general education institution shall be the next: to assist proper professional development for teachers and their adaptation to new educational requirements; to provide conditions for stimulation of their motivation for self-education, self-development, self-improvement and personal fulfillment; to create a strong need for psychological and pedagogical knowledge for teachers and development of

Revised Version Manuscript Received on October 15, 2019.

Liliia Martynets, Vasyl Stus Donetsk National University, Vinnytsia, Ukraine, (Email: liliamart7@gmail.com)

Hanna Davydenko, Open International University of Human Development «Ukraine», Vinnytsia, Ukraine, (Email: ganna.davydenko@gmail.com)

Iryna Denysovets, National University «Yuri Kondratyuk Poltava Polytechnic», Poltava, Ukraine, denysovets.ira@gmail.com

Sandeep Kumar Gupta, Corresponding Author, Sharda University, Greater Noida, U.P, India, (Email: skguptabhu@gmail.com) their practical skills; to provide continuing education; to engage teachers into interactive co-operation in order to develop professionally significant personal qualities that would assist creative personal fulfillment of each of them.

The aim of the article is to reveal parameters, factors and criteria of evaluation of teachers' professional development by school heads and define the results of the assessment of teachers` professional development parameters by administration of experimental and controlled general education institutions.

\section{MAIN BODY}

Professional development of a teacher is a lengthy and diverse process. Proper identification of fields related to the future development of a pedagogue, relevant managerial, scientific and methodological, and, occasionally, psychological assistance, and providing the teaching staff with motivation depend on a headmaster and a vice-principal. It implies diagnostic assessment of a teacher's performance and is relevant and significant in terms of improvement of teaching process and system of further teacher training, more expanded and efficient meeting their professional requirements and needs within the system of professional activity.

As a system of methods and tools aimed at exploring a teacher`s competencies, pedagogical diagnostics provides a framework for addressing difficulties in the course of work, conduces to realization and finding effective ways to solve them. Nonetheless, it also enables to define a teacher's strengths, as well as to design means and methods to secure and expand them within the frame of individual teaching style.

Scientific analysis allows systematizing component parts of a teacher`s work. In particular, V. Prykhodko [12] singles out such factors of a teacher's activities in educational institution as pedagogic activity, communication in education, and personality of a pedagogue. These factors, in their turn, are divided into the following: professional knowledge; pedagogic skills initial for self-diagnosis and self-maintained formation of this aspect of teaching; professional psychological orientation; psychological qualities sufficient for implementation of this aspect of teaching and new psychological formations occurred during the process; a mental map displaying the state of the aspect. 
In their researches G. Yelnikova and A. Petrenko distinguish the next factors (the main activities of a headmaster): to provide with continuing education; to implement social development of a general education institution; to develop an own social activity; personal qualities of a headmaster; official duties [2; 10].

Psychology experts consider educational process as a complex multilevel dynamic system consisted of the following building blocks:

1) the aim of professional pedagogical activity. It implies personality development consistent in harmony with oneself, society and nature, and the participation in cultural values. Thus, the aim serves as a special mission which purposes are formation and cultural self-determination of an individual, sense of identity.

2) the content of educational activity. It covers a process of organizing educational activities of students, aimed at their mastering of object sociocultural experience as the basis and conditions for the development; the process of organizing own activity;

3) tools of teaching activity. They include scientific knowledge (theoretical and empirical ones); textbooks and results of students`self-instructional observations as sources of knowledge; additional tools ( technical, graphical, computer ones)

4) the result of teaching activity. It is the development of students, along with their personal, intellectual improvement, development as an individual and the subject of teaching activity.

5) a subject of teaching activity. It is a teacher, whose tools of influence is personality, knowledge, skills, feelings and will.

6) an object of pedagogical activity. It is specific because a student is an object and a subject simultaneously, whereas teaching and educational process can be considered as efficient only if elements of self-development and self-education are combined. Moreover, pedagogical activity affects not only a student but a pedagogue as well developing some traits and eliminates the other.

The structure of pedagogical activity can be schematically described the next way: defining pedagogical aims and objectives; choice of tools and approaches to accomplish set objectives (Whom to teach? Who is to teach? What to teach? How to teach?); analysis and evaluation of pedagogical activity (a comparison study of what is planned and implemented in a teaching activity). If considering the activity of a teacher more broadly, along with mentioned elements which mainly implemented during school time, propedeutic and nonschool hours should also be taken into account [5].

Russian psychologist N. Kuzmina [4] distinguishes the next interrelated components in the structure of pedagogical activity:

1) the constructive component. It is associated with selection and composition of the educational material consistent with age and individual peculiarities of students, planning and developing the teaching process, defining a structure of own actions and deeds, designing educational and material basis for the implementation of educational process.
2) the organizational component. It implies the involvement of students in various activities, the organization of the students` group and transforming it into a tool of pedagogical influence;

3 ) the communicative component. The essence of it consists in establishing pedagogically reasonable relations with students, colleagues, parents, members of the community;

All these components are manifested in the course of work of a pedagogue of any speciality. In order to provide their successful implementation one needs such corresponding talents and skills as communicative, organizational, constructive, perceptual, suggestive, didactive, cognitive, self-regulatory ones.

Modern requirements for a teacher are documented in the Law of Ukraine "On General Secondary Education": "A educational worker should be an individual of high moral qualities, who has a respective pedagogical education, professional qualification of an educational worker, an appropriate level of professional training, performs pedagogical activities, ensures performance and quality of their work, whose physical and psychological health allows to perform professional duties at institutions of the system of general secondary education" [3]. One of the most important requirements is the clarity of social and professional attitude, in which a teacher acts precisely as a subject of pedagogical activity [5].

An attitude of a pedagogue reveals personality, social orientation, a type of social behavior and public activity. It is foremost for a pedagogue's activity to be humanistic i.e. characterized by love for children, protection of their rights and interests, their physical and mental health care, empathy for each of them, dialogic communication.

The fundamental regulatory document, that defines the requirements for academic workers of various categories, including for teachers, is the qualification characteristic of a specialist. Each group of requirements consists of three paragraphs: "Official duties", "One must know", "The requirements for qualification in terms of remuneration". On the basis of the qualification characteristic (i. e. labor market requirements) and the requirements of society regarding socially important qualities of university graduates, the education and qualification characteristic, a list of the main competencies, is being formed. According to the developed qualification characteristics of educational workers, they can be divided into the following categories: "specialist", "second category specialist", "first category specialist", "the highest category specialist".

The set of professionally driven requirements for a teacher is defined as professional readiness for pedagogical activities. It implies psychological, psychophysiological readiness, along with academic and practical training as a cornerstone of professionalism.

The content of professional readiness as a reflection of the aim of pedagogical education is accumulated in a professiogram. Professiogram (from Latin professio speciality and Greek gramma - stroke, writing) of an

Published By: 
educator`s identity - is an ideal portrait of a teacher, a model, a paragon that represents personal traits a teacher must obtain, and knowledge, competencies and skills crucial for implementation of pedagogical functions [5].

A remarkable experience gained in the formation of professiogram enables us to combine the professional requirements for a teacher into next main interrelated complexes:

a) civic virtues. They are: open-mindedness, integrity, the courage of convictions, civic engagement, sense of purpose, responsibility, patriotism, humanism, optimism, faith in humanity and own strengths; hard-working nature; the urge for life-long education and readiness for it;

b) qualities determined by the specificity of the profession of a teacher. It concerns professionally significant personal traits that characterize the intellectual, emotional and volitional aspects of an identity, substantively affect the result of professional activity and determine the individual style of teaching ("the trademark"). First of all, they are love for children; honesty, conscientiousness, justice, objectivity; staunchness, stamina, patience and self-possession; exactingness; emotional intelligence; adequate perception of children and attention to them; tact, tolerance; organizational skills, the ability to work with children, creative thinking, pedagogical intuition and observation; high standarts of speech (phonetic clarity, emotionality, expressiveness, meaningful speech); social skills, physical and mental stamina; adequate job performance; capacity to get quickly oriented in difficult pedagogical situations;

c) special knowledge, competencies and skills on the subject (specialty). Personal qualities in teaching process are inseparable from the professional ones, which are acquired in the process of mastering knowledge, skills, ways of thinking, work methods: subject-matter knowledge and mastery of methodology; physiological training; skills of using educational and teaching technologies; pedagogical tact and technic, communication skill.

Given qualities of a teacher guarantee proper implementation of professional functions and duties.

Professionally unacceptable qualities are: rudeness, irresponsibility, unprincipledness, incompetence in education and teaching matters, narrow-mindedness, low morality and spirituality, vengefulness, emotional instability, indifference to students and the subject.

The Statute on general education institution [11] clearly defines the legal status of educational workers, their professional rights and duties. Educational workers of general education institutions are entitled: to independently choose forms, methods, means of study, which are harmless to health of students; to participate in the work of methodological associations, meetings (conference) of the collective of the institution of education, events concerning organization of teaching and educational process; to choose forms of advance training; to conduct researches, experimental and pilot studies; to contribute suggestions on the improvement of teaching and educational process to the administration of a general education institution and the educational authorities; to receive social and financial security; to join trade unions and be a member of other civil society organizations not prohibited by law.
Educational workers of the general educational institution are obliged: to ensure an appropriate level of teaching academic disciplines in line with the curriculum, stick to the requirements of the State Standard of General Secondary Education; to contribute to development of interests, inclinations and talents of children, and their health maintenance as well; to assert respect for national symbols and principles of common morality by own example and edifications; to adhere the statute and internal regulations of the institution of education, terms of contract and labor agreement; to participate in an activity of the pedagogical council; to foster respect for parents, women, the elderly, national traditions and customs and cultural values of Ukrainians; to prepare studenti for independent life in keeping with mutual understanding, peace and unity within all the ethnical, national and religious groups; to observe pedagogical ethic and human decency, to respect dignity of pupils; to constantly enhance professional competences, teaching skills, general and political culture; to follow orders and instructions given by the head of an educational institution, education authorities.

Owing to personal qualities, skills essential for teaching are being acquired during professional training and practice subsequently. Combined with these skills, psychological and pedagogical qualities create a solid foundation for the development of pedagogical excellence.

Knowing about professionally significant personal qualities of a modern teacher and their role in professional practice will enable the head of the educational institution to detect the degree of their formation at a certain stage of professional development, and define ways of their further improvement. All personal qualities of an educator are interrelated and equally important. However, the worldview, personality orientation and motives that shape ones behavior and activities play the key role. It involves moral and social, professionally pedagogical and cognitive orientations.

Social and moral orientation. The Ukrainian pedagogue K. Ushinsky emphasizes that "The ultimate path of education of a person is the conviction, and the conviction can only be affected by another conviction. Any instructional program, any educational method, no matter how good they might be, when not embraced by a teacher, they remain a dead letter that does not present any efficiency. The firmest possible control is useless in this case. A teacher never can be a blind follower of instruction: not warmed by personal conviction, it has no power" [15, c. 168].

In a work process, ideological conviction determines social and moral orientations of a teacher, which is expressed in social needs, moral and value orientations, a sense of public duty and civic responsibility.

Professional and pedagogical orientation. It puts together the main professionally significant personal qualities of an educator which i.e. an interest in the profession, pedagogical vocation and inclinations. An interest in teaching manifests itself in positive emotional relationships with children, their parents, pedagogical activity in general and its specific types, in aspiration to master pedagogical knowledge and attainments. 
Unlike pedagogical interest, which can be contemplative, pedagogical vocation implies vocation, that arise from realization of capacity to pedagogical work.The keystone of pedagogical vocation is love for children. According to V. Sukhomlynsky, "Love for children - is flesh and blood of a teacher as a force capable to affect the inner world of another human being. A pedagogue without love for children is the same as a voiceless singer, a deaf musician or a painter without a sense of color" [13, c. 12]. It is about wise, kind, demanding love that teaches the way how to live. Such fundamental quality is a prerequisite for self-improvement, purposive self-development, and many professionally significant qualities that characterize professional and pedagogical orientation of a teacher.

Pedagogical inclinations represent strong desires and aspirations to devote oneself to pedagogical activity. The one who is indifferent to own work cannot be a good teacher. Children unmistakably spot teachers which do not fond of them and teaching in general.

Pedagogical duty and responsibility also belong to the most important qualities. Led by them, teachers are always ready to help everyone who needs it. They are self-demanding; adhere to the specific pedagogical moral code and professional dignity. Dedication of a teacher is the apex of pedagogical duty.

Personal qualities characterizing the professionally and pedagogical orientation build the authority of the teacher i.e. the recognition of intellectual, moral strength and leadership of the teacher by students. An authoritative pedagogue should be erudite, just, tolerant, principled, humane person with a high sense of responsibility. The ability to behave in a dignified manner, vivacity, cheerfulness, the serenity of mind, composure and affability of a teacher, sensible, intellectual and, not least, physical attractiveness are equally important as well.

Cognitive orientation is underpinned by spiritual needs and interests. One of the manifestations of spiritual and cultural needs of a teacher is the thirst for knowledge. Love for the subject is nearly the most crucial factor of the cognitive interest. According to L. Tolstoy, "if you want to educate a student with the study, you should love and know this subject yourself, then students will be fond of you and you will educate them; but if you loathe it, no matter how long you force them to learn, the study won't exert any educational influence" [14, c. 125]. A modern teacher should be well versed in different fields of the discipline he or she teaches, aware of new researches, inventions and hypotheses, recognize current and future prospects of science, master the culture of scientific and pedagogical thinking.

The personality of a teacher as a specialist is characterized by the following qualities: professional competence, pedagogical culture, pedagogical excellence, professional and pedagogical competency, pedagogical skills, professional and pedagogical potential, pedagogical technic and pedagogical creativity.

As an integral personal quality professional competence represents result of a teacher`s creative pedagogical activity, capacity to productively and correctly solve social, professional and personal tasks.

Pedagogical culture is the highest manifestation of professional competence of a teacher and comprises such components as: scientific erudition; general culture; pedagogical thinking; pedagogical ethics; the high culture of speech; communication culture; spiritual wealth; culture of occupational health; scientific management of labor; pursuit of self-development. Pedagogical culture should be purposefully shaped and constantly developed since it ensures advancement of the educational process and self-improvement of each teacher. The higher professional culture of the teacher is, the more diverse and effective an interaction with pupils is. It enables a teacher to reach the acme of skill.

Pedagogical excellence is a fusion of scientific knowledge, attainments and skills, art of methodology and personal traits of a teacher. Pedagogical excellence is based on a high professional level of a pedagogue, along with high general culture and pedagogical experience. Resulted from long-standing pedagogical experience and creative self-development, this quality enables to achieve remarkable results at minimal expenses of an educator and students energy. When interacting with the high-skilled pedagogue, children do not notice that they are being educated and taught, instead, they just want to attend classes, meet and communicate with an erudite, intelligent, kind and wise person - the teacher. In order to master pedagogical excellence, one should constantly refine oneself, internalizing pedagogical experience, mastering new training and education technics, and shaping own exact professional position.

An important element of pedagogical excellence is a humanistic orientation of activity, that involves a teacher's focus on the personality of another human being, vindication of the higher spiritual values, moral standards of behavior and relationships in word and in deed. Every teacher should be a humanist, recognize the importance of personality of each student, and build relationships with children based on love and respect.

The initial thesis of the professional activity of a humanist teacher is the understanding that all students are different. There are quick- and slow-witted children, disciplined kids and bullies, quite and sharp-tongued, pretty and not very likable, healthy and sickly ones. But teachers must be the best ones able to teach, stand for interests of students, assist them, create a healthy environment for self-affirmation and self-development of each of them.

As we can see, the model of professional activity of a teacher of a general education institution will consist of several groups of qualities, including specifying characteristics of these groups. Groups of a teacher's qualities will be considered as factors, while specifying characteristics as criteria.

The analysis of the scientific and pedagogical literature enables us to distinguish five main groups of characteristics of a school teacher which fully reveal the activity.

1. Continuing education. The competence requirements, updating professional knowledge of the professional activity, the development of professional skills, the level of proficiency in professional language, and systematic 
vocational education and training fall into this group

2. Personal characteristics of a teacher. Among other previously mentioned qualities we separate social and organizational skills, organizational and personal qualities.

3. Official duties. Here we single out the main group of characteristics regulating the content of teacher's professional activity: knowledge and application of laws and regulations on education, The Ministry of Education and Science of Ukraine documents concerning education and training, and the state language in accordance with current language policy in Ukraine; creating conditions for students to internalize educational programs at a level of mandatory state requirements; implication of efficient forms, methods, tools of the educational process, grasp of the methodology of the subject teaching and an educational work, along with pedagogy, psychology, developmental physiology.

4. Creative pedagogical activity. Defined criteria of this factor are following: the development of fundamentally new approaches to education, training and development of pupils; modernization of the content, forms, methods and tools of the educational process in order to develop creativity of students, their talents and natural gifts; performing a systematic self-evaluation of professional activity, and carrying out scientific researches on the creative generalization of own experience and of colleagues, putting principles of pedagogy of cooperation into practice.

Under the conditions of the development of a democratic society, an important factor in the activity of teachers of a modern educational institution is their social activity. Therefore, the last factor that reflects and specifies a pedagogical activity can be a criterion that characterizes a teacher`s social orientation.

5. The development of a social activity of a teacher. Within a framework of this factor the decisive components are following: a direct participation in professional competitions and pedagogical trade fairs; presentations on training and education at pedagogical councils, meetings, methodological associations; representation of a general educational institution at conferences, meetings, in state authorities which are in charge of general secondary education, and in the media; cooperation with parents, the community, and moulding a positive public opinion about the activity of a general educational institution.

On the grounds of the analysis of the scientific and pedagogical literature, we defined that the evaluation of a teacher`s professional development conducted by the head of general education institution considering the following parameters: the readiness of a teacher of a general educational institution for pedagogical activity, the content of the activity of a teacher of a general educational institution, the result of the activity of a teacher of a general educational institution.

The parameter "The readiness of a teacher of a general educational institution for pedagogical activity" consists of the following factors: life-long education and personal qualities of a teacher. The parameter "Content of the activity of a teacher of a general educational institution" is determined by such factors as professional duties and creative pedagogical activity. The parameter "The result of the activity of the teacher of a general educational institution" implies a factor of the social activity of a teacher.

These factors are provided by relevant criteria, defined on the basis of the analysis of scientific and pedagogical literature on a specificity of the professional activity of an educational worker of a general educational institution.

The factor of "Continuing Education" is represented by the following criteria: qualification requirements; updating professional knowledge of the professional activity; development of the expertise in professional activities; level of professional language culture; systematic continuing education and training.

The "Personal qualities of a teacher" factor is described by such criteria: communication skills; organizational skills; personal qualities.

The factor of "Official duties" implies the following criteria: knowledge and application of laws and regulations on education, The Ministry of Education and Science of Ukraine documents conserning education and training, and the state language in accordance with current language policy in Ukraine; creating conditions for students to internalize educational programs at a level of mandatory state requirements; implication of efficient forms, methods, tools of the educational process, grasp of the methodology of the subject teaching and educational work, along with pedagogy, psychology, developmental physiology.

The factor of "Creative pedagogical activity" contains the following criteria: the development of fundamentally new approaches to education, training and development of pupils; modernization of the content, forms, methods and tools of the educational process in order to develop creativity of students, their talents and natural gifts; performing a systematic self-evaluation of professional activity, and carrying out scientific researches on the creative generalization of own and colleagues`experience, putting principles of pedagogy of cooperation into practice.

The factor "Social activity of a teacher" is disclosed in the following criteria: direct participation in professional competitions and pedagogical trade fairs; presentations on training and education at pedagogical councils, meetings, methodological associations; representation of a general educational institution at conferences, meetings, in state authorities which are in charge of general secondary education, and in the media; cooperation with parents, the community, and moulding a positive public opinion about the activity of a general educational institution.

\section{THE DISCUSSION ON THE RESULTS}

Diagnostics of the parameters of professional development of teachers, in the view of heads of educational institutions, determinates the level of the readiness for pedagogical activity of a teacher, the content and the result of the teaching activity. Comparative data on the parameters of professional development of teachers for experimental and control groups at the beginning and after the experiment are shown in Table 1. 
Table 1

Summarized results of the evaluation of parameters of professional development of teachers by heads of schools of experimental and control general educational institutions

\begin{tabular}{|c|c|c|c|c|c|c|}
\hline \multirow{2}{*}{ Parameters } & \multicolumn{3}{|c|}{ Control group } & \multicolumn{3}{c|}{ Experimental group } \\
\cline { 2 - 7 } & initial value & final value & growth & initial value & final value & growth \\
\hline $\begin{array}{c}\text { The readiness of a teacher of } \\
\text { GEI for pedagogical activity }\end{array}$ & 0,172 & 0,173 & 0,001 & 0,170 & 0,240 & 0,06 \\
\hline $\begin{array}{c}\text { The content of an activity of } \\
\text { a teacher of GEI }\end{array}$ & 0,137 & 0,147 & 0,01 & 0,127 & 0,242 & 0,11 \\
\hline $\begin{array}{c}\text { The result of an activity of a } \\
\text { teacher of GEI }\end{array}$ & 0,112 & 0,139 & 0,027 & 0,139 & 0,274 & 0,13 \\
\hline Total $\Sigma$ & 0,421 & 0,460 & 0,039 & 0,436 & 0,755 & 0,319 \\
\hline Levels & moderate & moderate & $9,1 \%$ & moderate & high & $42,0 \%$ \\
\hline
\end{tabular}

Changes occurred in the process of professional development of teachers from the experimental group are due to using contemporary, effective methods and forms of influence on the professional development of teachers, the implementation of the development program "Professional development of teachers", etc. It can be stated that teachers from the experimental group obtained comprehensive knowledge in professional activities, are able to solve work situations, demonstrate an interest in productive creative activity, apply efficient forms, methods, tools of the educational process, put the principles of cooperative pedagogy into practice. It arises, primarily, due to the content of the activity that directed at the professional development of the teacher. School masters note that teachers have become more proactive, independent, and creative within the class time and extracurricular activities.

The results suggest that indices of the parameter of a teacher's readiness for pedagogical activity has increased among teachers from the experimental group by $29.3 \%$ compared with the ascertaining experiment, the content of the teacher's activity - by $47.5 \%$, (the result of teacher's activity - by $492 \%$ ). In comparison with the ascertaining experiment, the changes in the control group are insignificant: indices of the parameter of the content of a teacher's activity increased by $6.9 \%$, the result of a teacher's activity - by $19.5 \%$. The teacher's readiness for pedagogical activity remained virtually unchanged $(0.9 \%)$ (Table 1$)$.

Figure 1 illustrates the dynamics of all parameters of the professional development of teachers of general education institutions according to the heads of schools which took part in the experiment:

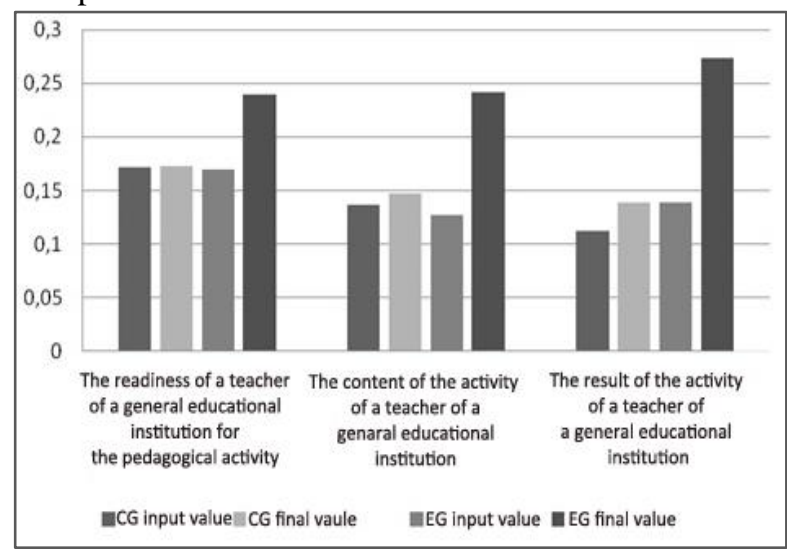

Fig. 1. The dynamics of evaluation of parameters of professional development of teachers from esperimental and controlled group by heads of schools
Comparison of quantitative estimators suggest that the total of parameters in experimental educational institutions increased by $42.0 \%$ (high level). In the control group, the results did not undergo considerable changes: the initial diagnosis showed that the total of the parameters changed by $9.1 \%$ (the average level remained). For a full picture of the obtained results we depicted them graphically (Fig. 2):

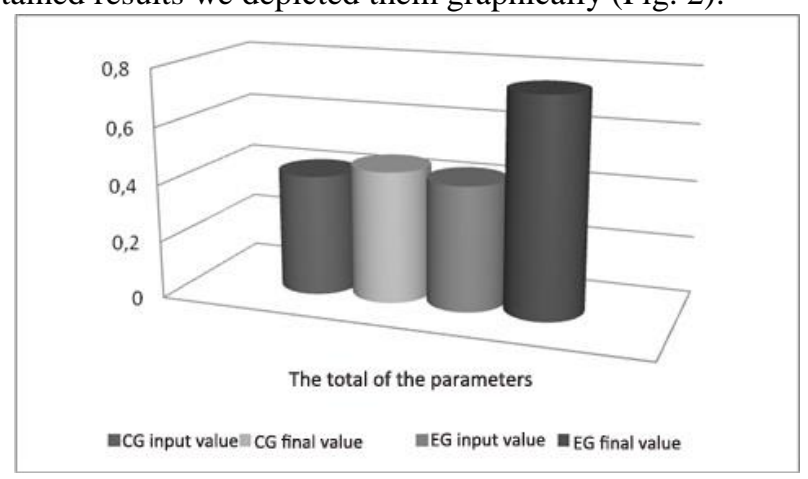

Fig. 2. Summarized results of the evaluation of parameters of professional development of teachers by heads of schools of experimental and control general educational

\section{CONCLUSION}

The analysis of the results obtained during the initial and final diagnosis is carried out using STATISTICA, a data analysis software system, and data analysis tools of "Statistics in Pedagogy", a computer program.

The determination of the probability of convergences and divergences for the experimental data was conducted according to the following algorithm:

- calculation for comparable data samples of the empirical value of the Cemp criterion;

- comparison of the Camp with the critical value of Ccrit;

- to summarize: where Cemp $\leq$ Ccrit the characteristics of the experimental and control groups converge with a significance point of 0.05 ; where Cemp $>$ Ccrit, the probability of divergences in the characteristics of the first and second data samples is $95 \%$. That is, if independent samples of initial states of the experimental and control groups coincide, but the final ones are different, it can be concluded that the effect of changes is precisely due to the

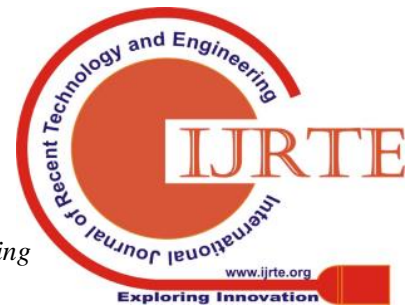


use of the experimental technique.

- linked samples Cemp> Ccrit suggest that the probability of divergences in the characteristics of the initial and final state of the experimental or control group makes 95\%; Cemp $\leq$ Ccrit - characteristics of the initial and final state converge with the significance point of 0.05 .

When analyzing the results of the research, the following criteria were calculated:

1) Student's t-test that determines the probability of the difference of mean values in two samples (t-Std);
2) Wilcoxon-Mann-Whitney test that shows arbitrary pairwise divergences in the characteristics of samples in the ratio scale $(\mathrm{W})$;

3) Cramer-Welch test, that determines the difference of the arithmetic mean of two samples (V);

The results of testing the homogeneity of the experimental and control groups at the stage of input diagnostics and the probability of convergences and divergences of the characteristics of the initial and final state by comparing statistical coefficients (t-Std, W, V) with their statistical criteria (tcrit, Wcrit, Vcrit) are given in Table 2:

Table 2

The determination of the probability of convergences and divergences of the evaluation characteristics of professional development of teachers from experimental and control groups conducted by heads of schools

\begin{tabular}{|c|c|c|c|c|c|c|c|c|c|c|c|c|}
\hline \multirow{3}{*}{\begin{tabular}{|c|} 
Criteria \\
Parameters \\
\end{tabular}} & \multicolumn{4}{|c|}{ t-Std } & \multicolumn{4}{|c|}{ W } & \multicolumn{4}{|c|}{$\mathbf{V}$} \\
\hline & $\mathrm{C}_{\mathrm{i}} \rightarrow \mathrm{E}_{\mathrm{f}}$ & $\mathrm{E}_{\mathrm{i}} \rightarrow \mathrm{E}$ & $\mathrm{C}_{\mathrm{i}} \rightarrow \mathrm{C}$ & $\mathrm{C}_{\mathrm{f}} \rightarrow \mathrm{E}_{\mathrm{f}}$ & $\mathrm{C}_{\mathrm{i}} \rightarrow \mathrm{E}$ & $\mathrm{E}_{\mathrm{i}} \rightarrow \mathrm{E}$ & $\mathrm{C}_{\mathrm{i}} \rightarrow \mathrm{C}_{\mathrm{f}}$ & $\mathrm{C}_{\mathrm{f}} \longrightarrow \mathrm{E}_{\mathrm{f}}$ & $\mathrm{C}_{\mathrm{i}} \rightarrow \mathrm{E}_{\mathrm{i}}$ & $\mathrm{E}_{\mathrm{i}} \rightarrow \mathrm{E}_{\mathrm{f}}$ & $\mathrm{C}_{\mathrm{i}} \rightarrow \mathrm{C}_{\mathrm{f}}$ & $\mathrm{C}_{\mathrm{f}} \rightarrow \mathrm{E}_{\mathrm{f}}$ \\
\hline & 1 & 2 & 3 & 4 & 5 & 6 & 7 & 8 & 9 & 10 & 11 & 12 \\
\hline $\begin{array}{l}\text { The readiness of a teacher of } \\
\text { GEI for pedagogical activity }\end{array}$ & 0,403 & 5,292 & 1,000 & 2,674 & 0,105 & 2,731 & 0,053 & 1,995 & 0,404 & 4,321 & 0,066 & 2,674 \\
\hline $\begin{array}{c}\text { The content of an activity of a } \\
\text { teacher of GEI }\end{array}$ & 0,475 & 7,514 & 1,000 & 3,334 & 0,420 & 2,941 & 0,263 & 2,468 & 0,475 & 4,660 & 0,404 & 3,334 \\
\hline $\begin{array}{c}\text { The result of an activity of a } \\
\text { teacher of GEI }\end{array}$ & 0,655 & 5,196 & 1,000 & 3,000 & 0,577 & 2,021 & 0,577 & 2,021 & 0,655 & 3,000 & 0,655 & 3,000 \\
\hline Total & 0,229 & 5,580 & 1,715 & 6,542 & 0,218 & 1,964 & 1,091 & 1,964 & 0,229 & 6,361 & 0,640 & 6,543 \\
\hline
\end{tabular}

To determine the probability of convergences and divergences of the characteristics of experimental and control groups we formulate two statistical hypotheses: the hypothesis of no difference (null hypothesis), the hypothesis of the significance of differences (alternative hypothesis) (Fig. 3):

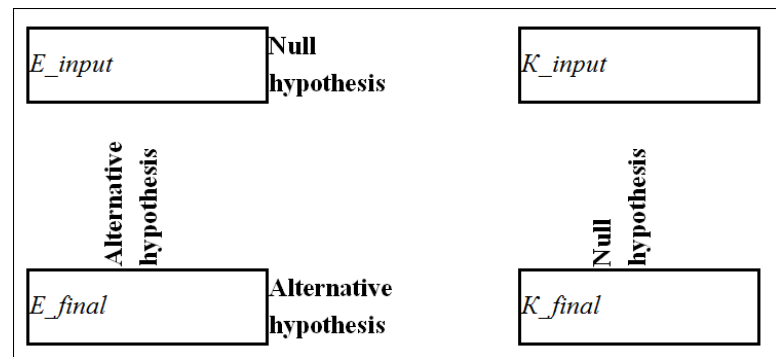

Fig.3. The determination of the probability of convergences and divergences of the groups characteristics

To decide which of the hypotheses should be accepted ,the empirical values of the statistical criterion of the characteristics of the experimental and control groups, which are calculated and listed in Table 2, must be compared with the known reference numbers, called the critical value of the criterion [1, p. 313, 306, 295].

When determining the critical values of statistical criteria, we are led by Dmitriy Novikov`s approach. According to the approach, in pedagogical studies these criteria are commonly limited to the significance point (error probability) - 0.05, i.e. no more than $5 \%$ of the error probability allowed [9, p. 44].
Thus, the critical values of the statistical criteria used for the comparison equal: $\mathrm{t}_{0.05}=1.96 ; \mathrm{V}_{0.05}=1.96 ; \mathrm{W}_{0.05}=1.96$.

As a result of comparison of empirical and critical criteria, two options are possible:

1) the empirical value of the criterion is less than or equals the critical one - the null hypothesis is accepted; thus, the characteristics of the experimental and control groups coincide.

2) the empirical value of the criterion is more than the critical one - an alternative hypothesis is adopted; thus, it is considered that the probability of divergences in the characteristics of the experimental and control groups is $95 \%$.

Let us analyze the criteria for the comparative samples obtained during the statistical analysis: experimental and control groups at the beginning of the experiment; the experimental group at the beginning and after the completion of the experiment; control group at the beginning and after the completion of the experiment; experimental and control after the completion of the experiment.

Let us compare the numbers in the control and experimental groups before the start of the experiment first (Table 2, columns 1, 5, 9). The empirical criteria for computational results are less than the critical ones $\left(\mathrm{t}_{\mathrm{emp}} \leq\right.$ $\left.1.96 ; \mathrm{W}_{\mathrm{emp}} \leq 1.96 ; \mathrm{W}_{\mathrm{emp}} \leq 1.96\right)$. Thus, the convergence of the characteristics of the control and experimental groups before the experiment is taken at the significance level of 0.05 . 
Now compare the characteristics of the control and experimental groups after completion of the experiment (Table 2, columns 4, 8, 12). All empirical criteria exceeded their critical values $\left(\mathrm{t}_{\mathrm{emp}}>1.96 ; \mathrm{W}_{\mathrm{emp}}>1.96 ; \mathrm{W}_{\mathrm{emp}}>1.96\right)$. Hence, the alternative hypothesis is accepted.

Comparing measurement results of the experimental group at the beginning of the experiment and after its completion (Table 2, columns 2, 6, 10) implies acceptance of the alternative hypothesis. So, the certainty of differences in the characteristics of the control and experimental groups after the end of the experiment, and the experimental group before and after the experiment is 95\%, which speaks of non-homogeneity of these samples.

Statistical analysis of the results of the control group at the beginning of the experiment and after its completion shows that the null hypothesis is accepted for all measurements (Table 2, columns 3, 7, 11). That is, the characteristics of the control group are taken at the significance level of 0.05 , the initial and final states of the control group remained the same, which indicates that the characteristics of the control group are homogeneous.

Therefore, the initial (before the beginning of the experiment) results of the experimental and control groups coincide, while the final (after the end of the experiment) differ. On this basis, we can conclude that the effect of changes occurred with the experimental group is precisely due to the application of the experimental system of professional development of teachers in general education institutions created at the forming stage of the experiment.

\section{REFERENCES}

1. Ermolaev O. Yu. (2003) Matematicheskaya statistika dlya psihologov: uchenik [Mathematical statistics for psychologists: student]. Moscow

2. Elnikova H. V. (2008) Modeliuvannia upravlinskoi kompetentnosti kerivnyka zahalnoosvitnoho navchalnoho zakladu [Modeling of managerial competence of the head of a comprehensive educational institution].Image of the modern pedagogue, No 3-4 (82-83), pp. 3-8

3. The Law of Ukraine "On General Secondary Education" (1999). Vidomosty Verkhovnoi Rady (VVR), No 28

4. Kuzmina N. V. (1990) Professionalizm lichnosti prepodavatelya i mastera proizvodstvennogo obucheniya [The professionalism of the personality of the teacher and master of industrial training]. Moscow: Vysshaya Shkola

5. Markova A. K. (1993) Psihologiya truda uchitelya [Psyhology of a teacher`s work]. Moscow: Prosveshcheniye

6. Martynets L. A. (2017) Upravlinnia osvitnim seredovyshchem profesiinoho rozvytku vchyteliv $u$ zahalnoosvitnomu navchalnomu zakladi : monohrafiia [Management of the educational environment of professional development of teachers in a comprehensive educational institution: a monograph]. Vinnytsia: TOV «Nilan-LTD», $408 \mathrm{p}$.

7. Martynets L. A. (2016) Upravlinnia profesiinym rozvytkom uchyteliv : navch.-metod. posib [Management of professional development of teachers: teaching and methodical manual]. Vinnytsia: TOV «Nilan-LTD», $87 \mathrm{p}$.

8. Natsionalna stratehiia rozvytku osvity v Ukraini na period do 2021 roku [National Strategy for the Development of Education in Ukraine until 2021]. Available at: http://zakon0.rada.gov.ua/laws/show/344/2013(accessed: 13.08.2017).

9. Novikov D. A. (2004) Statisticheskie metodyi v pedagogicheskih issledovaniyah (tipichnyie sluchai)
[Statistical methods in pedagogical research (typical cases)] Moscow: MZ-Press, $67 \mathrm{p}$.

10. Petrenko A. A. (2007) Orhanizatsiino-pedahohichni zasady atestatsii kerivnykiv zahalnoosvitnikh navchalnykh zakladiv : dys. ... kand. ped. nauk : 13.00.01 [Organizational-pedagogical principles of certification of heads of comprehensive educational institutions] ( $\mathrm{PhD}$ thesis). Kyiv, 209 p.

11. Polozhennia pro zahalnoosvitnii navchalnyi zaklad (2010)[Provisions on a general educational institution ] Osvita, pp. 3-9.

12. Prykhodko V. M. (2014) Profesiina kompetentnist vchytelia yak skladova monitorynhu yakosti osvitnoi diialnosti zahalnoosvitnoho navchalnoho zakladu [Professional competence of the teacher as a component of monitoring the quality of educational activity of a comprehensive educational institution] Science and Education a New Dimension. Pedagogy and Psychology, II (15), Issue 30, 2014.

13. Suhomlinskiy V. A. (1969) Pavlyishskaya srednyaya shkola [Pavlysh secondary school]. Moscow.

14. Tolstoy L.N. (1989) Pedagogicheskie sochineniya [Pedagogical writings] eds. N.V. Veykshan (Kudryavaya). Moscow: Pedagogika, 544 p.

15. Ushinskiy K. D.(1988) Pedagogicheskie sochineniya: v 6 t. [Pedagogical writings in $6 \mathrm{vol}$, vol. 1. Moscow : Pedagogika, $416 \mathrm{p}$. 